\title{
A Systematic Review of the Evidence Related to Mandated Nurse Staffing Ratios in Acute Hospitals
}

\begin{abstract}
Purpose

The purpose of this systematic review was to evaluate and summarise available research on nurse staffing methods and relate these to outcomes under three overarching themes of management of clinical risk, quality and safety; development of a new or innovative staffing methodology and equity of nursing workload.
\end{abstract}

\section{Method}

We used the PRISMA method and located articles by searching via the Griffith University Library electronic catalogue that included PubMed, CINAHL (Cumulative Index to Nursing and Allied Health) and Medline databases. Only English language publications were from 1 January 2010 to 30 April 2016 that focused on the methodologies in acute hospital inpatient units

\section{Results}

Two of the four staffing methods were found to have evidenced-based articles from empirical studies within the parameters set for inclusion. Of the four staffing methodologies searched supply and demand returned 10 studies and staffing ratios returned 11 studies

\section{Conclusions}

There is a need to develop an evidence-based nurse sensitive outcomes measures upon which staffing for safety, quality and workplace equity and an instrument that reliability and validly projects nurse staffing requirements in a variety of clinical settings. Additionally, this instrument must take into account clinical and other risks provides for time to pursue quality and safety of care and equity of workload as inextricable and primary considerations.

Keywords: "nurse staffing"; "nurse scheduling";" nurse rostering"; "staffing method"; "clinical risk"; "mandated nurse to patient ratios; "nursing quality"; "patient safety", "staffing equity". 


\section{What is known about the topic?}

Nurse staffing is a controversial topic that has significant has patient safety, quality of care, resources human and financial resource implications. In acute care services, nursing accounts for approximately $70 \%$ of salaries and wages paid health services budgets, and evidence as to efficacy and effectiveness of any staffing methodology is required and has workforce and industrial relations implications. While there is significant literature available on the topic, there is a paucity of empirical evidence supporting claims of increased patient safety while some evidence exists relating to equity of workload for nurses.

\section{What does this paper add?}

This paper provides a contemporary qualitative analysis of empirical evidence using the PRISMA method for conducting a systematic review of the available literature. It demonstrates a significant research gap to support claims of increased patient safety. The paper calls for greatly improved data sets upon which research can be undertaken to determine any association between mandated patient to nurse ratios and other staffing methodologies and patient safety and quality of care.

\section{What are the implications for practitioners?}

There is insufficient contemporary research to support staffing methodologies for appropriate staffing, balanced workloads and quality safe care. Such research would include the establishment of nurse-sensitive patient outcomes measurement, and more robust data sets are needed for empirical analysis to produce such evidence. 


\section{BACKGROUND}

Unit-based mandatory nurse staffing ratios has again become a topic of discussion relating to costs, efficacy and evidence available. There has been considerable academic discussion relating to the pros and cons of mandatory unit-based staffing ratios. However, questions remain as to what empirical evidence is available to underpin this staffing method as well as others. For the purpose of this qualitative analysis of the available literature, we used the definition of nurse adopted by the International Council of Nurses (ICN) in order to be clear about what is meant by the terms nursing skill-mix and nursing workload (1).

Internationally, California, USA, appears to be the first jurisdiction to introduce mandated unit-based minimum licensed nurse-to-patient ratios for acute hospitals via the Assembly Bill 394 in 1999. The implementation of this legislation has not had sufficient inquiry. Burnes-Bolton, Aydin (2) reported on their study which examined the impact of mandated nursing ratios in California on key measure of nursing quality among adults in acute care hospitals. They found that there was an expected increase in the proportion of licensed staff per patient but failed to demonstrate improvement in nursingsensitive patient outcomes identified for measurement in that study. Following the Californian law, 14 States in the USA have regulatory requirements for nurse staffing in hospitals ranging from requirements for staffing committees, generation of a core staffing plan or requiring disclosure by public reporting. However, only California stipulates maintenance of a required mandated nurse to patient ratio at all times at unit level (3)

Within Australia, a decision in the Australian State of Victoria was made to introduce legislation mandating a minimum staffing level staffing of five nurses to 20 patients in medical and surgical ward in 2001. A study by Gerdtz and Nelson (4) found that there was an urgent need for further research that specifically examines the relationships between models of staffing, skill mix and quality outcomes.

The Queensland Government has amended the Hospital and Health Boards Act, (Qld) 2011 Division 4, section 138 which now requires minimum ratios in public sector health service facilities. The Government has mandated minimum nursing staff ratios on a platform of patients receiving higher quality and safety of care thus setting minimum staffing standards for nursing care in hospitals and that nurses will have more manageable, safer workloads and increased job satisfaction (5). 
The Queensland legislation came into force on 1 July 2016 and requires a minimum staff to patient ratio of 1:4 for morning and afternoon shifts and 1:7 on night shifts to be maintained in prescribed medical, surgical and mental health units. Government policy is that these ratios will be introduced in stages across Queensland from 1 July 2016. The Government placed high expectations on the legislation regarding patient safety and quality of service from the patient perspective and the equity of workload for nurses. These expectations, coupled with the considerable opportunity cost associated with increased staffing costs, raises the reasonable question as to the evidence-base for mandatory nurse staffing ratios or any method of nurse staffing deployed?

There is significant debate in the literature and professional forums about the benefits and detriments of mandated staff ratios. Searching evidenced based literature using the Griffith University Library online search engines revealed zero records when filtered for peer-reviewed and academic/scholarly materials within the last five-year period.

Looking at literature older than five years, Buchan (6) asserts that the main weaknesses of using nurse: patient ratios is their relative inflexibility and their potential inefficiency if they are wrongly calibrated. However, Buchan (6) perceives that their strength lies in their simplicity and their transparency. There was no accompanying empirical evidence provided to support this assertion. Welton (7) claims that significant weakness in this type of regulatory approach is that hospitals are often required to increase the number of registered nurses without receiving increased reimbursement for patient care. The response to this lack of funding in hospitals results in a decrease the number of other staff, such as unlicensed assistive personnel and house keepers, to compensate for the increased staffing cost. Experience shows that this puts additional burdens on registered nurses as they are then forced to assume non-nursing care tasks. There was no empirical evidence available to support or refute this.

More recently, Tevington (8) supported mandatory nurse-patient ratios asserting that increasing registered nurses will increase positive patient outcomes, decrease nursing shortages and increase job satisfaction and cites several authors in support of this. Again, there is no disagreement with this with, the need to support his with evidence remains.

There are clear gaps in the health services and nursing management literature relating to staffing factors and patient safety, and very few well-designed intervention studies have been conducted ${ }^{(9)}$. Examining the literature for the 13 year period after the Haertsch article demonstrates that there has 
been little change. Brennan and colleagues (10) undertook a systematic review of the literature examining the relationship between nurse staffing and patient outcomes. They found that, at that time, no evidence-based nurse staffing guidelines existed and the few studies conducted reported variability in methods and measurement approaches which brought results into question.

There is little doubt that finding the balance of equitable rosters continues to be a challenge for the nursing workforce and health care organisations seeking to leverage evidence-based leadership practices ${ }^{(11-14)}$. Ratios and supply and demand strategies (referred to as 'subjective acuity strategies') for nurse-patient staffing continue to be the dominant approach in health care organisations ${ }^{(12,15-17)}$. In addition to ratio-based assignments and acuity-based assignment, some models are purely driven by financial targets ${ }^{(15)}$.

It is clear that there is a need for more emphasis on using evidence-based strategies to promote safety and quality for consumers of health care and to address workload and time and attendance equity for nurses. Robinson and colleagues (18) found that there is limited information about how staffing policies are interpreted and implemented by hospital leaders in their personnel and budgetary planning practices and that many outcomes of staffing were as a result financial imperatives which took little account of the process of nurse staffing. Previous studies measured outcomes of the processes that hospitals implemented in response to initiatives related to staffing, not the process of implementation itself. This fixed or historical approach to staffing is a common practice in health care services (18).

The literature revealed a further category of nurse staffing relating to the use and risks associated with casual per diem nursing labour from nursing agencies. Adams, Kaplow (19) describes this group as nurses who work for agencies as outside or external to a health care organisation. While this type of employment practice continues in most countries with a well-developed health system, Adams, Kaplow (19) cites recommendations from the Institute of Medicine (20) that health care facilities avoid employing nurses working from a temporary external agency due to this "augmenting risks to safety"(p.52). This staffing approach is labelled "Surge Staffing" for this qualitative review of the literature.

Four staffing methods were identified as a result of the search of the literature and used to categorise the studies that located during the search of the literature: 
1. Supply Demand

2. Ratio

3. Fixed/Historical

4. Surge

Analysis of the findings of the included studies in this qualitative reviewreview revealed three outcome themes Without reference to importance or numbers of papers included, the outcome themes were:

i. Management of clinical risk, quality and safety;

ii. Development of a new or innovative staffing methodology; and,

iii. Equity of nursing workload.

It was the intention of this study to correlate outcome themes with the staffing method categories that emerged.

\section{METHOD}

We used the PRISMA (Preferred Reporting Items for Systematic reviews and Meta-Analyses) statement proposed by Moher, Liberati (21). Relevant peer-reviewed and scholarly journal articles were located by searching via the Griffith University Library electronic catalogue that included PubMed, CINAHL (Cumulative Index to Nursing and Allied Health) and Medline databases.

For the search, keywords were formulated with the aid of Boolean operators "AND" and "OR" for combination of words and the search done using CINAHL and Medline using MESH.

Key words in combination used were;

i. Nursing staff/staffing AND Methodology - 3,982 articles

ii. Nursing staffing AND ratio $-5,706$ articles

iii. Nurse Staffing AND Safe $-5,796$ articles

iv. Nurse Rostering AND ratio -149 articles

v. Nurse Rostering AND Methodology -213 articles

vi. Nurse Rostering AND Safe -131 articles

Key words used when searching for scholarly articles using Google scholar were:

I. Nursing staff/staffing AND Methodology -134 articles 

II. Nursing staffing AND ratio - 16,901 articles
III. Nurse Rostering AND ratio $-4,980$ articles
IV. Nurse Rostering AND Methodology - 6,480 articles

\section{Selection of Evidence}

The initial screening was performed by examining the title and then abstract and conclusions to determine if the article reflected the objectives of the systematic literature review. Relevant peerreviewed and scholarly journal articles were located by searching the literature as previously described

\section{Inclusion and Exclusion Criteria}

Only English language publications were included and 1 January 2010 to 30 April 2016. The literature reviewed included journal articles, guidelines, case studies and government reports on the topic focusing on publications in the last six years. Publications selected included literature and systematic reviews as well as original research journal articles and reports.

The review focused on the available methodologies in inpatient wards of acute care hospitals and excludes those methodologies considered relevant for primary and community care, ambulatory care, sub-acute care, mental health care and aged care services. The screening process applied the inclusion and exclusion criteria to narrow the number of studies identified. Table 1 illustrates the inclusion and exclusion criteria applied to this study.

Table 1: Inclusion and exclusion criteria. This table illustrates the criteria used to include and exclude the reviewed literature.

\begin{tabular}{|c|c|}
\hline Inclusion: literature studied & Exclusion: literature disregarded \\
\hline - $\quad$ Ranging between 2010 and January 2016 & - Ambulatory staffing methodologies \\
\hline - Written in English & - $\quad$ Sub-acute care staffing methodologies \\
\hline $\begin{array}{l}\text { - Include other systematic reviews, meta- } \\
\text { analyses and case reports }\end{array}$ & - $\quad$ Aged Care staffing methodologies \\
\hline $\begin{array}{l}\text { - Available methodologies in inpatient } \\
\text { units of acute care hospitals }\end{array}$ & \\
\hline
\end{tabular}




\section{RESULTS AND DISCUSSION}

Following the application of the inclusion and exclusion criteria detailed in Table 1., a total of 214 records were identified. A further 120 duplicates were then removed. An additional screening process was applied based on the title of the articles, and a further 66 records were excluded leaving 54 records to for eligibility assessment. Screening of these articles proceeded based on the abstract to include only those articles which contained empirical evidence, and this resulted in excluding a further 33 articles. We undertook the qualitative analysis on the remaining 21 articles.
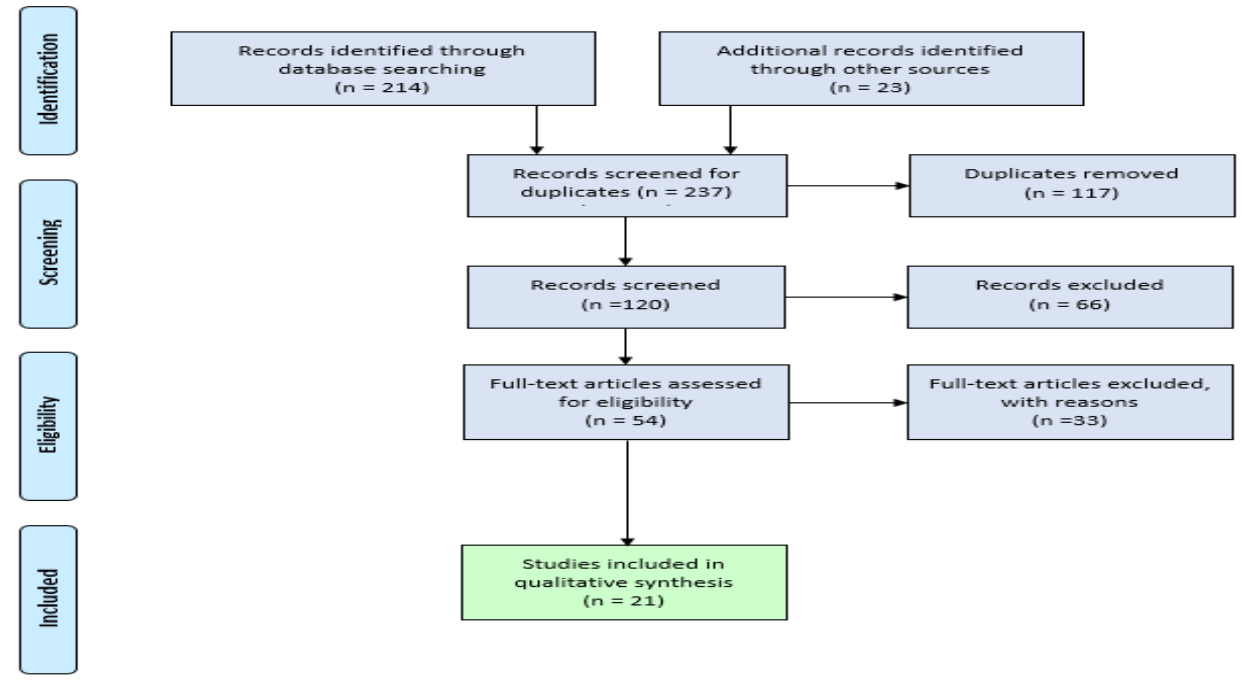

Figure 1: PRISMA diagram, summary of findings in the outcome level.

Following all exclusions as shown in Figure 1., only two of the four staffing methods were found to have evidenced-based articles from empirical studies within the parameters set for inclusion. There were no studies identified for fixed/historically based or for surge staffing models in the included studies for qualitative analysis. Supply and Demand returned 10 studies, and Staffing Ratio also returned 11 studies. Table 2 . shows these results

Table 2: Studies categorised by Staffing Method Type

\begin{tabular}{|c|c|l|}
\hline $\begin{array}{c}\text { Staffing } \\
\text { Method }\end{array}$ & $\begin{array}{c}\text { Number of } \\
\text { Studies }\end{array}$ & \multicolumn{1}{c|}{ Authors } \\
\hline $\begin{array}{c}\text { Supply and } \\
\text { Demand }\end{array}$ & 10 & $\begin{array}{l}\text { Graff, Goldschmidt (22); Braaksma, Burger (23); McNair (24); Pappas, } \\
\text { Davidson (25); Twigg, Cramer (26); Unruh and Zhang (27); Patrician, } \\
\text { Loan (28); Smeds Alenius, Tishelman (29); Diaz, Erkoc (30); Hoi, Ismail } \\
\text { (31). }\end{array}$ \\
\hline $\begin{array}{c}\text { Staffing } \\
\text { Ratio }\end{array}$ & 11 & $\begin{array}{l}\text { Jones, Heui Bae (32); Rogowski, Staiger (33); Mefford L and Alligood } \\
\text { M. (34) Park, Blegen (35); Sherenian, Profit (36); Smeds Alenius, } \\
\text { Tishelman (29) McHugh, Brooks Carthon (37); Cook, Gaynor (38); } \\
\text { Harding and Wright (39); Ball J and Catton H. (40); Aiken L. et.al. (41) }\end{array}$ \\
\hline
\end{tabular}


A common theme of the Supply and Demand type of staffing methodology studies revealed the need to collect detailed information about fluctuating patient demand. However, there was little agreement between the studies on what information ought to be collected. Numerous studies highlighted the need to collect patient data at the care level if there is to be a better understanding of the dynamic interactions between nursing staff and patients and the effect on both parties.

Many of the Staffing Ratio studies also discussed skill-mix with the assumption that higher levels of skill-mix resulted in improved patient outcomes. Studies by Cook, Gaynor (38) and McHugh, Brooks Carthon (37) regarding the consequences of the Californian mandated nursing ratios concluded that there was no evidence that legislation resulted in an improvement in patient safety or a reduction in skill-mix. We evaluated a number of the studies as addressing more than one theme. Thus some papers were found to address more than one theme. Table 3 . lists the authors of these studies against each of the outcomes themes.

Table 3: Outcome themes emerging in the literature included in the Systematic Literature Review by Author *

\begin{tabular}{|c|c|l|}
\hline Theme & $\begin{array}{c}\text { No. } \\
\text { Studies }\end{array}$ & \multicolumn{1}{c|}{ Authors } \\
\hline $\begin{array}{c}\text { Management of clinical } \\
\text { risk, quality and safety. }\end{array}$ & 11 & $\begin{array}{l}\text { Pappas, Davidson (25); Rogowski, Staiger (33); Unruh and } \\
\text { Zhang (27); Mefford and Alligood (34); Park, Blegen (35); } \\
\text { Patrician, Loan (28); Sherenian, Profit (36); Smeds Alenius, } \\
\text { Tishelman (29); Cook, Gaynor (38); Dubois, D'Amour (42): } \\
\text { Aiken, Sloane (41) }\end{array}$ \\
\hline $\begin{array}{c}\text { Development of a new or } \\
\text { innovative staffing } \\
\text { methodology. }\end{array}$ & 10 & $\begin{array}{l}\text { Graff, Goldschmidt (22); Jones, Heui Bae (32); Braaksma, } \\
\text { Burger (23); McNair (24); Pappas, Davidson (25); Twigg, } \\
\text { Cramer (26); McHugh, Brooks Carthon (37); Diaz, Erkoc } \\
\text { (30); Harding and Wright (39). }\end{array}$ \\
\hline $\begin{array}{c}\text { Equity of nursing } \\
\text { workload. }\end{array}$ & 7 & $\begin{array}{l}\text { Jones, Heui Bae (32); McNair (24); Pappas, Davidson (25); } \\
\text { Rogowski, Staiger (33); Harding and Wright (39); Hayes and } \\
\text { Ball (43); Hoi, Ismail (31); Hayes and Ball (44). }\end{array}$ \\
\hline \multicolumn{2}{|c|}{}
\end{tabular}

*some studies addressed more than one theme.

The majority of the outcome themes were related to the management of clinical risk, quality and safety. A number of the studies in this area concluded that there appears to be a correlation between skill-mix and positive patient outcomes. A total of 10 outcome themes discussed new or an innovative 
staffing methodologies. The majority of the studies were concerned about developing a nurse staffing model with limited discussion regarding patient outcomes. However, in similarity with previous studies, a number acknowledged the limitation of the data in undertaking the research. Seven of the studies discussed the outcome theme of equity in staffing with several of them concluding that there is a wide variation in nurse staffing and skill-mix. The study by Harding and Wright ${ }^{(39)}$ suggest that the quality of patient care may vary between facilities in New South Wales due to staffing variations. Again, there is no disagreement with this assertion however it is still without an evidence-base.

Table 4. combines the staffing methods and outcome themes in a matrix format.

Table 4: Observed Theme by Method Matrix *

\begin{tabular}{|l|c|c|c|c|}
\hline \multicolumn{1}{|c|}{ Type } & $\begin{array}{c}\text { Quality \& } \\
\text { Safety }\end{array}$ & $\begin{array}{c}\text { Staffing } \\
\text { Methodology }\end{array}$ & $\begin{array}{c}\text { Equity in } \\
\text { Staffing }\end{array}$ & Total \\
\hline Supply and Demand & 4 & 6 & 3 & 13 \\
\hline Staffing Ratio & $\mathbf{7}$ & 4 & 4 & 15 \\
\hline Total & $\mathbf{1 1}$ & $\mathbf{1 0}$ & $\mathbf{7}$ & $\mathbf{2 8}$ \\
\hline
\end{tabular}

*some studies addressed more than one theme.

There was a total of seven staffing ratio studies that had quality and safety as part of their outcome themes $(29,33-36,38,41)$. The findings within these studies were diverse and often discussed the skill level of the nurse in conjunction with staffing ratio methodology. Once again, a common theme mentioned in a number of these studies was the need for objective data on which to base research. A large study was undertaken by Aiken and colleagues in Europe in 2014 regarding hospital mortality and nurses' workload ${ }^{(41)}$. The findings concluded that increasing a nursing workload by one patient increased the likelihood of an inpatient dying within 30 days of admission by $7 \%$. The same study also concluded that for every $10 \%$ increase in the nursing workforce that has a bachelor's degree decreases this likelihood by $7 \%$. This study did not address adverse and sentinel event data during the period of hospitalisation.

\section{CONCLUSION}

There is limited evidence to conclude that either supply and demand models of nurse staffing or a staffing ratios method improves the management of risk or improves quality and safety in patient 
care. Intuitively, it would be reasonable to assert that if there are more nursing staff at an appropriate skill mix level, this would improve patient care and equity in staffing levels.

Research undertaken in Europe by (41) demonstrates a clear relationship between skill mix and patient safety. The Aiken study also demonstrates an association between the ratio of the number of patients per nurse and some measures of patient safety. There is a significant research gap that requires attention of researchers to provide evidence to underpin assumptions regarding nursing ratios and patient safety.

Much of the research cited in this paper found considerable difficulties with accessing and using reliable data and thus validity of findings of many of these studies has been problematic. A common theme identified in many of the studies was the need to develop robust data on which to base future research. There is an urgent need for more research into this important area of the health workforce including the need for a valid and reliable measure of nursing workload. 


\section{BIBLIOGRAPHY}

1. Doyle S. ICN adopts new definition of nurse. AORN Journal. 1976;23(2):165-6.

2. Burnes-Bolton L, Aydin C, Donaldson N, Brown DS, Sandhu M, Fridman M, et al. Mandated nurse staffing ratios in California: a comparison of staffing and nursing-sensitive outcomes pre- and postregulation. Policy Polit Nurs Pract. 2007;8(4):238-50.

3. American Nurses Association. Nurse Staffing 2015 [Available from:

http://www.nursingworld.org/MainMenuCategories/Policy-Advocacy/State/Legislative-AgendaReports/State-StaffingPlansRatios.

4. Gerdtz MF, Nelson S. 5-20: a model of minimum nurse-to-patient ratios in Victoria, Australia. J Nurs Manag. 2007;15(1):64-71.

5. Queensland Government. Nurse to patient ratio legislation introduced Brisbane: Queensland Government; 2015 [Available from: http://statements.qld.gov.au/Statement/2015/12/1/nurse-topatient-ratio-legislation-introduced.

6. Buchan J. A certain ratio? The policy implications of minimum staffing ratios in nursing. Journal of Health Services Research \& Policy. 2005;10(4):239-44.

7. Welton J. Mandatory Hospital Nurse to Patient Staffing Ratios: Time to Take a Different Approach. The Online Journal of Issues in Nursing. 2007;12(3).

8. Tevington P. Mandatory nurse-patient ratios. Medsurg nursing : official journal of the Academy of Medical-Surgical Nurses. 2011;20(5):265.

9. Haertsch MW, . Safe staffing and patient safety: literature review : final report. Canberra, A.C.T. U6 - ctx_ver=Z39.88-2004\&ctx_enc=info\%3Aofi\%2Fenc\%3AUTF-

8\&rfr_id=info\%3Asid\%2Fsummon.serialssolutions.com\&rft_val_fmt=info\%3Aofi\%2Ffmt\%3Akev\%3A

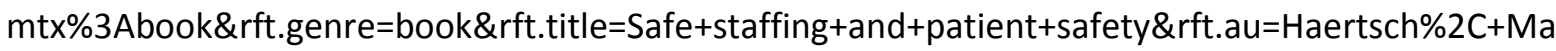
ggie\&rft.au=Weeks\%2C+Charmaine\&rft.date $=2003-01-$

01\&rft.pub=Australian+Council+for+Safety+and+Quality+in+Health+Care\&rft.externalDoclD=b15663 036\&paramdict=en-US U7 - Book: Australian Council for Safety and Quality in Health Care; 2003.

10. Brennan C, Daly B, Jones K. State of the science: the relationship between nurse staffing and patient outcomes. West J Nurs Res. 2013;35(6):760-94.

11. Chiaramonte MV, Chiaramonte LM. An agent-based nurse rostering system under minimal staffing conditions. International Journal of Production Economics. 2008;114(2):697-713.

12. Maenhout B, Vanhoucke M. The Impact of Incorporating Nurse-Specific Characteristics in a Cyclical Scheduling Approach. The Journal of the Operational Research Society. 2009;60(12):1683-98.

13. Maenhout $B$, Vanhoucke M. An integrated nurse staffing and scheduling analysis for longerterm nursing staff allocation problems. Omega. 2013;41(2):485-99.

14. Tsai C-C, Li SHA. A two-stage modeling with genetic algorithms for the nurse scheduling problem. Expert Systems With Applications. 2009;36(5):9506-12.

15. Gray J, Kerfoot K. Expanding the Parameters for Excellence in Patient Assignments: Is Leveraging an Evidence-Data-Based Acuity Methodology Realistic? Nursing administration quarterly. 2016;40(1):7-13.

16. Marcinko D, Hetico H. Hospitals \& health care organizations: management strategies, operational techniques, tools, templates, and case studies. Boca Raton: Taylor \& Francis/CRC Press; 2013.

17. Wagner KD, Johnson KL, Hardin-Pierce MG. High-acuity nursing. Boston: Pearson; 2010.

18. Robinson C, Annis A, Forman J, Krein SL, Yankey N, Duffy S, et al. Factors that affect implementation of a nurse staffing directive: results from a qualitative multi-case evaluation. J Adv Nurs. 2016;72(8):1886-98.

19. Adams J, Kaplow R, Dominy J, Stroud B. Beyond a Band-Aid Approach: An Internal Agency Solution to Nurse Staffing. Nurs Econ. 2015;33(1):51-8.

20. Medicine llo. Keeping patients safe: Transforming the work environment of nurses. Washington. D.C.: National Academies Press; 2003.

21. Moher D, Liberati A, Tetzlaff J, Altman D. Preferred reporting items for systematic reviews and meta-analyses: the PRISMA statement. J Clin Epidemiol. 2009;62(10):1006-12. 
22. Graff I, Goldschmidt B, Glien P, Klockner S, Erdfelder F, Schiefer JL, et al. Nurse Staffing Calculation in the Emergency Department - Performance-Oriented Calculation Based on the Manchester Triage System at the University Hospital Bonn. PLoS One. 2016;11(5):e0154344.

23. Braaksma A, Burger CAJ, Kortbeek N, Boucherie RJ, Bakker PJM. Flexible nurse staffing based on hourly bed census predictions. International journal of production economics. 2015;161:167-80.

24. McNair D. Enhancing Nursing Staffing Forecasting With Safety Stock Over Lead Time Modeling. Nurs Adm Q. 2015;39(4):291-6.

25. Pappas S, Davidson N, Woodard J, Davis J, Welton JM. Risk-Adjusted Staffing to Improve Patient Value. NURSING ECONOMICS. 2015;33(2):73-.

26. Twigg D, Cramer J, Pugh J. Nurse Staffing and Workload Drivers in Small Rural Hospitals: An imperative for Evidence. Online Journal of Rural Nursing and Health Care. 2016;16(1):97-121.

27. Unruh L, Zhang N. Nurse staffing and patient safety in hospitals: new variable and longitudinal approaches. Nurs Res. 2012;61(1):3-12.

28. Patrician PA, Loan L, McCarthy M, Brosch LR, Davey KS. Towards Evidence-based Management: Creating an Informative Database of Nursing-Sensitive Indicators. Journal of Nursing Scholarship. 2010;42(4):358-66.

29. Smeds Alenius L, Tishelman C, Runesdotter S, Lindqvist R. Staffing and resource adequacy strongly related to RNs' assessment of patient safety: a national study of RNs working in acute-care hospitals in Sweden. BMJ Qual Saf. 2014;23(3):242-9.

30. Diaz D, Erkoc M, Asfour S, Baker E. New ways of thinking about nurse scheduling. Journal of Advances in Management Research. 2010;7(1):76-93.

31. Hoi S, Ismail N, Ong L, Kang J. Determining nurse staffing needs: the workload intensity measurement system. J Nurs Manag. 2010;18(1):44-53.

32. Jones T, Heui Bae S, Murry N, Hamilton P. Texas Nurse Staffing Trends Before and After Mandated Nurse Staffing Committees. Policy, politics \& nursing practice. 2015;16(3-4):79-96.

33. Rogowski JA, Staiger DO, Patrick TE, Horbar JD, Kenny MJ, Lake ET. Nurse Staffing in Neonatal Intensive Care Units in the United States: NICU NURSE STAFFING. Research in Nursing \& Health. 2015;38(5):333-41.

34. Mefford L, Alligood M. Evaluating nurse staffing patterns and neonatal intensive care unit outcomes using Levine's Conservation Model of Nursing. J Nurs Manag. 2011;19(8):998-1011.

35. Park S, Blegen M, Spetz J, Chapman S, De Groot H. Comparison of Nurse Staffing Measurements in Staffing-Outcomes Research. Med Care. 2015;53(1):e1-8.

36. Sherenian M, Profit J, Schmidt B, Suh S, Xiao R, Zupancic JA, et al. Nurse-to-patient ratios and neonatal outcomes: a brief systematic review. Neonatology. 2013;104(3):179-83.

37. McHugh M, Brooks Carthon M, Sloane D, Wu E, Kelly L, Aiken L. Impact of nurse staffing mandates on safety-net hospitals: lessons from California. Milbank Q. 2012;90(1):160-86.

38. Cook A, Gaynor M, Stephens M, Jr., Taylor L. The effect of a hospital nurse staffing mandate on patient health outcomes: evidence from California's minimum staffing regulation. J Health Econ. 2012;31(2):340-8.

39. Harding $T$, Wright $M$. Unequal staffing: A snapshot of nurse staffing in critical care units in New South Wales, Australia. Contemporary Nurse. 2015;47(1-2):7-15.

40. Ball J, Catton H. Planning nurse staffing: are we willing and able? Journal of Research in Nursing. 2011;16(6):551-8.

41. Aiken LH, Sloane DM, Bruyneel L, Heede KVd, Griffiths P, Busse R, et al. Nurse staffing and education and hospital mortality in nine European countries: a retrospective observational study. Lancet. 2014;383(9931):1824-30.

42. Dubois C-A, D'Amour D, Tchouaket E, Clarke S, Rivard M, Blais R. Associations of patient safety outcomes with models of nursing care organization at unit level in hospitals. International journal for quality in health care : journal of the International Society for Quality in Health Care / ISQua. 2013;25(2):110.

43. Hayes N, Ball J. Achieving safe staffing for older people in hospital. Nursing older people. 2012;24(4):20. 
44. Hayes N, Ball J. Achieving safe staffing for older people in hospital. Nurs Older People. 2012;24(4):20-4. 